\title{
Effects of Gamdutang on Protection Against Accumulation of Cadmium in Rats
}

\author{
In-Sook Lee $\cdot$ Young-Chae Cho* ${ }^{*}$ \\ Department of Public Health, Graduate School of Chungnam National University \\ *Department of Preventive Medicine and Public Health, College of Medicine, Chungnam National University, \\ and Research Institute for Medical Sciences \\ (Received September 17, 2008/Revised September 30, 2008/Accepted October 13, 2008)
}

\begin{abstract}
These experiments were conducted to determine the effects of Gamdutang on the accumulation of cadmium in the body of groups of rats that received an 8 -week administration of 1.7,3.4 and $6.8 \mu \mathrm{g} / \mathrm{g} / \mathrm{day}$ of cadmium, respectively, while the other groups of rats received an 8-week administration of a mixture of cadmium by concentration and Gamdutang. A comparative analysis of these groups was conducted in respect of weight, accumulated cadmium in blood and diverse organs and pathological findings from the kidneys. As for the cadmium accumulation in blood, livers, kidneys, and testis, with the lengthening of the experiment period, the cadmium and Gamdutang mixtureadministered groups tended to have reduced accumulation levels compared with the groups exclusively administered cadmium. Histopathological observation of the kidneys, observed in the cadmium exclusively administered groups showed hemorrhagic necrosis in glomeruli, swelling of tubules, epithelial shedding and necrosis of tubules; however, only mild tissue lesions were observed in the cadmium and Gamdutang mixture-administered groups. Given the above results, Gamdutang is deemed to have the effects of reducing the accumulation of cadmium in blood, liver, and testis when low-concentration cadmium is administered to rats.
\end{abstract}

Keywords: Cadmium, Accumulation, Blood, Liver, Kidney, Testis, Rat

\section{Introduction}

Of pollutants created as a result of humans' industrial activities and every day lives, heavy metal substances, if humans are exposed to them in a long time, will accumulate in the body, inflicting adverse impacts on it.

Cadmium toxication in the body varies according to exposure amounts, chemical forms, exposure periods, and bodily absorption pathways, ${ }^{1,2)}$ cadmium toxication is generally known to cause disorders in the kidney, impairment to liver tissues, disorders in the central nerve, osteoporosis, osteomalacia, and hypertension, among other diseases. ${ }^{3-5)}$ Also, it was reported that cadmium hampers the activation of

Corresponding author: Department of Preventive Medicine and public Health, College of Medicine, Chungnam National University

Tel: 82-42-580-8265, Fax: 82-42-583-7561

E-mail: choyc@cnu.ac.kr diverse metalloenzymes in the body, impairs erythrocyte and thus retards its growth, and causes congenital malformation. ${ }^{6,7)}$

Cadmium is absorbed into the body mostly through the respiratory organs and the gastrointestinal tract, and except for its absorption into the respiratory system due to occupational exposure, cadmium is generally absorbed into the gastrointestinal system through foods ${ }^{8}$. $50 \sim 85 \%$ of cadmium absorbed into the body is known to be accumulated in the kidney and the liver, ${ }^{9-11)}$ and it exists mostly in the form of metallothionein. ${ }^{12)}$

According to existing research into the protective effects against cadmium absorbed into the body, there are several reports that necrosis in testis caused by cadmium is protected against by zinc, ${ }^{13,14)}$ as well as a report that selenium also powerfully protects against the damage to the testis. ${ }^{15)}$ However, there has been little research into the effects of bio-substances with little side 
effects of restraining cadmium toxicity. ${ }^{16)}$ Thus, this research aims to study the effects of Gamdutang on cadmium accumulation in the body; Gamdutang, made from extracts of licorice and black adzuki beans, has been drunk as a herb medicine for detoxication for a long period of time, thereby proving its stability. Previous research into Gamdutang includes a study on Gamdutang's effects of reducing lead toxication in rats, ${ }^{17)}$ a study on carbon tetrachloride's effects of easing liver toxication ${ }^{18)}$ and a study on Gamdutang having the effect of restraining the growth of cancerous cells in the in vitro cell toxication experiment, ${ }^{19)}$ however, no research has been conducted to study Gamdutang's effects of reducing cadmium accumulation in the body.

Thus, in an effort to determine the effects of Gamdutang administered into the body on the absorption and accumulation of cadmium in the body, this research conducted an array of experiments using rats, and significant results thereof are hereby reported.

\section{Materials and Methods}

\section{Experimental animals}

Five-week-old Sprague-Dawley male rats (Samtaco Bio-Korea Co, Korea), as bought, were made to undergo a week of adjustment and being raised in the laboratory. Afterwards, of them, 140 rats whose weight was $205.0 \mathrm{~g} \pm 2.8$, and that were clinically acceptable, were used as experimental animals. The animal raising environment provided a temperature of $24 \pm 2^{\circ} \mathrm{C}$, a relative humidity of $55 \pm$ $5 \%$, and artificial lighting with a 12-hour light/12hour dark cycle.

\section{Formulation of cadmium solution and Gam- dutang}

Powdered cadmium with a fineness of $99.5 \%$ (Cd; Sigma-Aldrich. Inc., USA) was melted, and was used as a cadmium solution (MOE, 2004). $8,000 \mathrm{~mL}$ Gamdutang was formulated by putting $3,000 \mathrm{~g}$ Seomoktae (a kind of black bean) and $3,000 \mathrm{~g}$ licorice into unwoven cloth, pouring $30 \mathrm{~L}$ water into it, and boiling it for four hours in a jar at $121^{\circ} \mathrm{C}$ under 1.5 pressure. ${ }^{20)}$ It was the absence of cadmium or other heavy metals in the formulated
Gamdutang.

\section{Deployment of experimental animals and} administering of cadmium and Gamdutang

Experimental animals were divided into seven groups, each of which consisted of 20 animals. After the experiment began, five rats per group were slaughtered and used for experiment in the 1st week, 2nd week, 4th week, and 8th week, respectively.

The control group was not administered with cadmium and Gamdutang, but administered orally with $3.5 \mathrm{~mL}$ distilled water every day. The cadmium exclusively administered groups - G-I-1, G-II-1 and G-III-1 - were orally administered every day with $3.0 \mathrm{~mL}$ distilled water; the groups administered with a mixture of cadmium and Gamdutang - G-I-2, G-II-2 and G-III-2 - were orally administered every day with a mixture of $3.0 \mathrm{~mL}$ Gamdutang and cadmium solution with cadmium solution amounting to $1.7 \mu \mathrm{g}, 3.4 \mu \mathrm{g}$ and $6.8 \mu \mathrm{g}$, respectively, per gram of rat's weight (Table 1).

\section{Measuring rats' weight and collection of test samples}

Rats' weight was measured once on the first day of every week after the experiment began, using a balance (CAS, Computing Scale, Korea) in order to observe a change in the weight.

For the collection of blood and diverse organs, in the 1st week, 2nd week, 4th week, and 8th week after the experiment commenced, five rats per each group were anesthetized with ethyl ether; hearts were punctured, about $5 \mathrm{~mL}$ blood was taken from there, while the abdomens were incised, and livers, kidneys, and testis were extracted to be used in the experiment.

5. Measuring cadmium concentration in blood and organs

Each of blood and organs was weighed precisely at $1 \mathrm{~g}$, to which $5 \mathrm{~mL} \mathrm{HNO}_{3}$ was added, then organic substances were decomposed using the Microwave Sample Preparation System (MDS2100: CEM Corporation, America). The cadmium concentration was measured using the Atomic Absorption Spectrophotometer (Varian 280FS, Varian Co, USA). 
Table 1. Experimental design for treatment of cadmium and Kamdutang

\begin{tabular}{lcccccc}
\hline \hline \multirow{2}{*}{ Group } & \multirow{2}{*}{ Treatment } & \multicolumn{5}{c}{ Number of rats at first day of experimental week } \\
\cline { 3 - 7 } & & 1 wk & 2 wk & 4 wk & 8 wk & Total \\
\hline Control & DW & 5 & 5 & 5 & 5 & 20 \\
G-I-1 & Cd $1.7 \mu \mathrm{g} / \mathrm{g}+\mathrm{DW}$ & 5 & 5 & 5 & 5 & 20 \\
G-I-2 & $\mathrm{Cd} 1.7 \mu \mathrm{g} / \mathrm{g}+\mathrm{KD}$ & 5 & 5 & 5 & 5 & 20 \\
G-II-1 & $\mathrm{Cd} 3.4 \mu \mathrm{g} / \mathrm{g}+\mathrm{DW}$ & 5 & 5 & 5 & 5 & 20 \\
G-II-2 & $\mathrm{Cd} 3.4 \mu \mathrm{g} / \mathrm{g}+\mathrm{KD}$ & 5 & 5 & 5 & 5 & 20 \\
G-III-1 & $\mathrm{Cd} 6.8 \mu \mathrm{g} / \mathrm{g}+\mathrm{DW}$ & 5 & 5 & 5 & 5 & 20 \\
G-III-2 & $\mathrm{Cd} 6.8 \mu \mathrm{g} / \mathrm{g}+\mathrm{KD}$ & 5 & 5 & 5 & 5 & 20 \\
\hline & Total & 35 & 35 & 35 & 35 & 140 \\
\hline
\end{tabular}

: Distilled water, : Kamdootang

Table 2. Weekly change of body weight of rats after the cadmium is orally administered in distilled water or in Gamdutang

\begin{tabular}{cccccccc}
\multicolumn{1}{c}{} & \multicolumn{1}{c}{ (Unit: g, Mean \pm SE) } \\
\hline \hline Week/Group & Control & G-I-1 & G-I-2 & G-II-1 & G-II-2 & G-III-1 & G-III-2 \\
\hline 1 & $256.9 \pm 1.7$ & $246.2 \pm 3.2^{* *}$ & $249.5 \pm 3.8$ & $238.5 \pm 2.9^{* *}$ & $252.9 \pm 2.9$ & $229.5 \pm 3.0^{* *}$ & $228.3 \pm 2.4^{* *}$ \\
4 & $292.1 \pm 4.5$ & $266.6 \pm 4.0^{* *}$ & $279.9 \pm 4.1$ & $273.4 \pm 4.8^{* *}$ & $292.4 \pm 5.7$ & $261.5 \pm 4.6^{* *}$ & $256.3 \pm 2.8^{* *}$ \\
8 & $341.9 \pm 8.2$ & $301.1 \pm 6.3^{* *}$ & $321.3 \pm 6.2$ & $322.7 \pm 4.3^{*}$ & $341.4 \pm 5.5$ & $316.2 \pm 6.3^{*}$ & $311.7 \pm 5.9^{*}$ \\
\hline$p$-value & $422.0 \pm 11.9$ & $369.5 \pm 7.9^{*}$ & $409.5 \pm 10.7$ & $379.7 \pm 7.0^{*}$ & $405.2 \pm 13.5$ & $361.4 \pm 5.0^{* *}$ & $361.5 \pm 9.3^{* *}$ \\
\hline
\end{tabular}

G-I-1 : Cd $1.7 \mu \mathrm{g} / \mathrm{g}+\mathrm{DW}, \mathrm{G}-\mathrm{I}-2: \mathrm{Cd} 1.7 \mu \mathrm{g} / \mathrm{g}+\mathrm{GD}$

G-II-1 : Cd $3.4 \mu \mathrm{g} / \mathrm{g}+\mathrm{DW}, \mathrm{G}-\mathrm{II}-2: \mathrm{Cd} 3.4 \mu \mathrm{g} / \mathrm{g}+\mathrm{GD}$

G-III-1 : Cd $6.8 \mu \mathrm{g} / \mathrm{g}+\mathrm{DW}$, G-III-2 : Cd $6.8 \mu \mathrm{g} / \mathrm{g}+\mathrm{GD}$

$*: \mathrm{p}<0.05, * *: \mathrm{p}<0.01$ : Significantly different from the control group.

\section{Histopathological findings of kidneys}

For histopathological observation, kidneys were extracted, were dyed with hematoxylin-eosin (H\&E), and were observed using the optical microscope (Polyvar, Reichert-Jung, Germany).

\section{Statistical analysis}

Data were analyzed using the SPSSWIN (Ver 13.0) statistical program. The significance was verified through t-test and ANOVA, and the correlation between variables was reviewed using the Pearson correlation coefficient. The significance level of all statistics was set at $\mathrm{p}<0.05$.

\section{Results}

\section{A change in weight following the adminis- tration of Gamdutang}

The weight of the control group and each test group was compared. The cadmium exclusively administered groups - G-I-1, G-II-1, and G-III-1 compared with the control group, tended to decrease their weight significantly; however, the cadmium and Gamdutang mixture-administered groups - G-I-2 and G-II-2 - did not show a significant change in weight, while G-III-2 showed a significant decrease in weight (Table 2).

\section{Accumulation of cadmium in blood following the administration of Gamdutang}

The cadmium accumulation was compared between the cadmium exclusively administered groups, and the cadmium and Gamdutang mixtureadministered groups. In the case of G-I-1 and G-I2 groups, the cadmium exclusively administered groups showed a significantly high level of cadmium accumulation in the 2 nd week, 4 th week and 8th week, compared with the cadmium and 
Table 3. Cadmium levels of blood in the rats after the cadmium is orally administered in distilled water or in Gamdutang for 1 to 8 weeks

(Unit: $\mu \mathrm{g} / \mathrm{g}, \mathrm{Mean} \pm \mathrm{SE}$ )

\begin{tabular}{ccccccc}
\hline \hline Week/Group & G-I-1 & G-I-2 & G-II- & G-II-2 & G-III-1 & G-III-2 \\
\hline 1 & $0.000 \pm 0.000$ & $0.000 \pm 0.000$ & $0.017 \pm 0.001^{* *}$ & $0.005 \pm 0.000$ & $0.055 \pm 0.004^{*}$ & $0.034 \pm 0.005$ \\
2 & $0.016 \pm 0.001^{*}$ & $0.011 \pm 0.001$ & $0.037 \pm 0.002^{* *}$ & $0.025 \pm 0.002$ & $0.066 \pm 0.002^{* *}$ & $0.038 \pm 0.004$ \\
4 & $0.023 \pm 0.002^{* *}$ & $0.015 \pm 0.001$ & $0.048 \pm 0.004^{* *}$ & $0.026 \pm 0.002$ & $0.082 \pm 0.003^{* *}$ & $0.054 \pm 0.004$ \\
8 & $0.056 \pm 0.002^{* *}$ & $0.038 \pm 0.001$ & $0.087 \pm 0.004^{* *}$ & $0.061 \pm 0.005$ & $0.145 \pm 0.008^{* *}$ & $0.094 \pm 0.003$ \\
\hline$p$-value & 0.000 & 0.000 & 0.000 & 0.000 & 0.000 & 0.000 \\
\hline
\end{tabular}

G-I-1 : Cd $1.7 \mu \mathrm{g} / \mathrm{g}+\mathrm{DW}, \mathrm{G}-\mathrm{I}-2: \mathrm{Cd} 1.7 \mu \mathrm{g} / \mathrm{g}+\mathrm{KD}$

G-II-1 : Cd $3.4 \mu \mathrm{g} / \mathrm{g}+\mathrm{DW}, \mathrm{G}-\mathrm{II}-2: \mathrm{Cd} 3.4 \mu \mathrm{g} / \mathrm{g}+\mathrm{KD}$

G-III-1 : Cd $6.8 \mu \mathrm{g} / \mathrm{g}+\mathrm{DW}, \mathrm{G}-\mathrm{III}-2$ : Cd $6.8 \mu \mathrm{g} / \mathrm{g}+\mathrm{KD}$.

*: $\mathrm{p}<0.05, * *: \mathrm{p}<0.01$ : Significantly different between the group 1 and group 2 of G-I, G-II and G-III.

Table 4. Cadmium levels of liver in the rats after the cadmium is orally administered in distilled water or in Gamdutang for 1 to 8 weeks

\begin{tabular}{ccccccc}
\hline \hline Week/Group & G-I-1 & G-I-2 & G-II-1 & G-II-2 & G-III-1 & G-III-2 \\
\hline 1 & $1.084 \pm 0.097$ & $1.306 \pm 0.091$ & $2.210 \pm 0.117$ & $2.612 \pm 0.193$ & $4.287 \pm 0.246$ & $4.116 \pm 0.251$ \\
2 & $2.353 \pm 0.184$ & $2.412 \pm 0.187$ & $3.457 \pm 0.259$ & $4.222 \pm 0.257$ & $5.825 \pm 0.302$ & $7.314 \pm 0.512$ \\
4 & $5.167 \pm 0.374^{*}$ & $3.933 \pm 0.279$ & $9.550 \pm 0.375^{*}$ & $7.330 \pm 0.749$ & $14.548 \pm 0.615$ & $13.429 \pm 0.392$ \\
8 & $7.747 \pm 0.406^{* *}$ & $5.887 \pm 0.392$ & $18.583 \pm 0.841^{* *}$ & $14.068 \pm 0.694$ & $26.941 \pm 1.513$ & $24.740 \pm 1.157$ \\
\hline$p$-value & 0.000 & 0.000 & 0.000 & 0.000 & 0.000 & 0.000 \\
\hline
\end{tabular}

G-I-1 : Cd $1.7 \mu \mathrm{g} / \mathrm{g}+\mathrm{DW}, \mathrm{G}-\mathrm{I}-2: \mathrm{Cd} 1.7 \mu \mathrm{g} / \mathrm{g}+\mathrm{KD}$

G-II-1 : Cd $3.4 \mu \mathrm{g} / \mathrm{g}+\mathrm{DW}, \mathrm{G}-\mathrm{II}-2$ : Cd $3.4 \mu \mathrm{g} / \mathrm{g}+\mathrm{KD}$

G-III-1 : Cd $6.8 \mu \mathrm{g} / \mathrm{g}+\mathrm{DW}, \mathrm{G}-\mathrm{III}-2: \mathrm{Cd} 6.8 \mu \mathrm{g} / \mathrm{g}+\mathrm{KD}$.

*: $\mathrm{p}<0.05, * *: \mathrm{p}<0.01$ : Significantly different between the group 1 and group 2 of G-I, G-II and G-III.

Gamdutang mixture-administered groups. In the case of G-II-1, G-II-2, G-III-1 and G-III-2 groups, during the entire experiment period, the cadmium exclusively administered groups showed a significantly high level of cadmium accumulation compared with the cadmium and Gamdutang mixtureadministered groups (Table 3).

\section{Accumulation of cadmium in liver following the administration of Gamdutang}

In all groups of the cadmium exclusively administered groups and the cadmium and Gamdutang mixture-administered groups, accumulation of cadmium in livers tended to increase with the cadmium and Gamdutang mixture-administered groups in the $1 \mathrm{st}$ and 2 nd weeks, compared with the cadmium exclusively administered groups; in the 4th and 8th weeks, accumulation of cadmium tended to increase with the cadmium exclusively administered groups, compared with the cadmium and Gamdutang mixture-administered groups. In the case of G-I-1, G-I-2, G-II-1, and G-II-2 groups, in the 4th and 8th weeks, the cadmium exclusively administered groups showed a significantly high level of cadmium accumulation compared with the cadmium and Gamdutang mixture-administered groups (Table 4).

\section{Accumulation of cadmium in kidney follow- ing the administration of Gamdutang}

In all groups of the cadmium exclusively administered groups and the cadmium and Gamdutang mixture-administered groups, in the 1 st and 2nd weeks, accumulation of cadmium tended to increase with the cadmium and Gamdutang mixture-administered groups, compared with the cadmium exclusively administered groups. In the 4th and 8th weeks, accumulation of cadmium tended to increase with the cadmium exclusively administered groups compared with the cadmium 
Table 5. Cadmium levels of kidney in the rats after the cadmium is orally administered in distilled water or in Gamdutang for 1 to 8 weeks (Unit: $\mu \mathrm{g} / \mathrm{g}$, Mean $\pm \mathrm{SE}$ )

\begin{tabular}{ccccccc}
\hline \hline Week/Group & G-I-1 & G-I-2 & G-II-1 & G-II-2 & G-III-1 & G-III-2 \\
\hline 1 & $0.873 \pm 0.084$ & $0.987 \pm 0.067$ & $1.735 \pm 0.103$ & $2.083 \pm 0.132$ & $3.168 \pm 0.254$ & $3.634 \pm 0.233$ \\
2 & $2.045 \pm 0.101$ & $1.984 \pm 0.103$ & $2.874 \pm 0.208$ & $3.639 \pm 0.322$ & $5.265 \pm 0.237$ & $5.561 \pm 0.379$ \\
4 & $4.649 \pm 0.215$ & $4.673 \pm 0.383$ & $8.052 \pm 0.791$ & $7.708 \pm 0.316$ & $12.531 \pm 0.592$ & $11.921 \pm 0.624$ \\
8 & $8.905 \pm 0.457$ & $7.914 \pm 0.460$ & $18.673 \pm 1.512$ & $15.469 \pm 0.637$ & $28.495 \pm 1.844$ & $27.632 \pm 1.566$ \\
\hline$p$-value & 0.000 & 0.000 & 0.000 & 0.000 & 0.000 & 0.000 \\
\hline
\end{tabular}

G-I-1 : Cd $1.7 \mu \mathrm{g} / \mathrm{g}+\mathrm{DW}, \mathrm{G}-\mathrm{I}-2: \mathrm{Cd} 1.7 \mu \mathrm{g} / \mathrm{g}+\mathrm{KD}$

G-II-1 : Cd $3.4 \mu \mathrm{g} / \mathrm{g}+\mathrm{DW}, \mathrm{G}-\mathrm{II}-2$ : Cd $3.4 \mu \mathrm{g} / \mathrm{g}+\mathrm{KD}$

G-III-1 : Cd $6.8 \mu \mathrm{g} / \mathrm{g}+\mathrm{DW}, \mathrm{G}-\mathrm{III}-2: \mathrm{Cd} 6.8 \mu \mathrm{g} / \mathrm{g}+\mathrm{KD}$.

Table 6. Cadmium levels of testis in the rats after the cadmium is orally administered in distilled water or in Gamdutang for 1 to 8 weeks

\begin{tabular}{ccccccc}
\hline \hline Week/Group & G-I-1 & G-I-2 & G-II-1 & G-II-2 & G-III- & G-III-2 \\
\hline 1 & $0.061 \pm 0.009$ & $0.081 \pm 0.008$ & $0.144 \pm 0.010$ & $0.183 \pm 0.015$ & $0.272 \pm 0.016$ & $0.300 \pm 0.027$ \\
2 & $0.127 \pm 0.010$ & $0.134 \pm 0.009$ & $0.258 \pm 0.016$ & $0.268 \pm 0.015$ & $0.377 \pm 0.017$ & $0.399 \pm 0.031$ \\
4 & $0.197 \pm 0.016$ & $0.218 \pm 0.020$ & $0.282 \pm 0.015$ & $0.321 \pm 0.030$ & $0.432 \pm 0.048$ & $0.577 \pm 0.052$ \\
8 & $0.419 \pm 0.042^{*}$ & $0.292 \pm 0.023$ & $1.342 \pm 0.054$ & $1.146 \pm 0.078$ & $1.814 \pm 0.115$ & $1.523 \pm 0.078$ \\
\hline$p$-value & 0.000 & 0.000 & 0.000 & 0.000 & 0.000 & 0.000 \\
\hline
\end{tabular}

G-I-1 : Cd $1.7 \mu \mathrm{g} / \mathrm{g}+\mathrm{DW}, \mathrm{G}-\mathrm{I}-2: \mathrm{Cd} 1.7 \mu \mathrm{g} / \mathrm{g}+\mathrm{KD}$

G-II-1 : Cd $3.4 \mu \mathrm{g} / \mathrm{g}+\mathrm{DW}, \mathrm{G}-\mathrm{II}-2: \mathrm{Cd} 3.4 \mu \mathrm{g} / \mathrm{g}+\mathrm{KD}$

G-III-1 : Cd $6.8 \mu \mathrm{g} / \mathrm{g}+\mathrm{DW}, \mathrm{G}-\mathrm{III}-2: \mathrm{Cd} 6.8 \mu \mathrm{g} / \mathrm{g}+\mathrm{KD}$.

*: p $<0.05$ : Significantly different between the group 1 and group 2 of G-I, G-II and G-III.

and Gamdutang mixture-administered groups but the difference was not statistically significant (Table 5).

\section{Accumulation of cadmium in testis following the administration of Gamdutang}

In all groups of the cadmium exclusively administered groups and the cadmium and Gamdutang mixture-administered groups, in the 1st, 2nd and 4th weeks, accumulation of cadmium in testis tended to increase with the cadmium and Gamdutang mixture-administered groups compared with the cadmium exclusively administered groups. In the 8 th week, accumulation of cadmium tended to increase with the cadmium exclusively administered groups, compared with the cadmium and Gamdutang mixture-administered groups. In the case of G-I-1 and G-I-2 groups, in the 8th week, the cadmium exclusively administered groups showed a significantly high level of cadmium compared with the cadmium and Gamdutang mixture-administered groups (Table 6).

\section{Comparison of accumulation of cadmium in blood and diverse organs}

Accumulation of cadmium in blood and diverse organs was compared. In all test groups, in the 1st and 2nd weeks of the experiment, the organs' cadmium accumulation ranking was found to be livers, kidneys, testis and blood in this order. However, in the 8th week, the cadmium exclusively administered groups - G-I-1, G-II-1 and G-III-1 showed more accumulation of cadmium in the kidneys than in the livers, and their cadmium ranking was kidneys, livers, testis, and blood in this order. The cadmium and Gamdutang mixtureadministered groups (G-I-2 and G-II-2), and GIII-2 showed more cadmium accumulation in the kidneys than in the livers in the 4th week and 8th week, respectively, and the cadmium accumulation ranking was kidneys, livers, testis and blood in this order (Table 7). 
Table 7. Cadmium levels in blood and internal organs of rats after the cadmium is orally administered in distilled water or in Gamdutang for 1 to 8 weeks

(Unit: $\mu \mathrm{g} / \mathrm{g}$, Mean $\pm \mathrm{SE}$ )

\begin{tabular}{cccccccc}
\hline \hline Week/Group & G-I-1 & G-I-2 & G-II-1 & G-II-2 & G-III-1 & G-III-2 \\
\hline \multirow{4}{*}{1} & Blood & $0.000 \pm 0.000$ & $0.000 \pm 0.000$ & $0.017 \pm 0.001$ & $0.005 \pm 0.000$ & $0.055 \pm 0.004$ & $0.034 \pm 0.005$ \\
& Liver & $1.084 \pm 0.097$ & $1.306 \pm 0.091$ & $2.210 \pm 0.117$ & $2.612 \pm 0.193$ & $4.287 \pm 0.246$ & $4.116 \pm 0.251$ \\
& Kidney & $0.873 \pm 0.084$ & $0.987 \pm 0.067$ & $1.735 \pm 0.103$ & $2.083 \pm 0.132$ & $3.168 \pm 0.254$ & $3.634 \pm 0.233$ \\
& Testis & $0.061 \pm 0.009$ & $0.081 \pm 0.008$ & $0.144 \pm 0.010$ & $0.183 \pm 0.015$ & $0.272 \pm 0.016$ & $0.300 \pm 0.027$ \\
\cline { 2 - 8 } & $p$-value & 0.000 & 0.000 & 0.000 & 0.000 & 0.000 & 0.000 \\
\hline \multirow{4}{*}{2} & Blood & $0.016 \mathrm{v} 0.001$ & $0.011 \pm 0.001$ & $0.037 \pm 0.002$ & $0.025 \pm 0.002$ & $0.066 \pm 0.002$ & $0.038 \pm 0.004$ \\
& Liver & $2.353 \pm 0.184$ & $2.412 \pm 0.187$ & $3.457 \pm 0.259$ & $4.222 \pm 0.257$ & $5.825 \pm 0.302$ & $7.314 \pm 0.512$ \\
& Kidney & $2.045 \pm 0.101$ & $1.984 \pm 0.103$ & $2.870 \pm 0.208$ & $3.639 \pm 0.322$ & $5.265 \pm 0.237$ & $5.561 \pm 0.379$ \\
& Testis & $0.127 \mathrm{v} 0.010$ & $0.134 \pm 0.009$ & $0.258 \pm 0.016$ & $0.268 \pm 0.015$ & $0.377 \pm 0.017$ & $0.399 \pm 0.031$ \\
\cline { 2 - 8 } p-value & 0.000 & 0.000 & 0.000 & 0.000 & 0.000 & 0.000 \\
\hline \multirow{4}{*}{4} & Blood & $0.023 \pm 0.002$ & $0.015 \pm 0.001$ & $0.048 \pm 0.004$ & $0.026 \pm 0.002$ & $0.082 \pm 0.003$ & $0.054 \pm 0.004$ \\
& Liver & $5.167 \pm 0.374$ & $3.933 \pm 0.279$ & $9.550 \pm 0.375$ & $7.330 \pm 0.749$ & $14.548 \pm 0.615$ & $13.429 \pm 0.392$ \\
& Kidney & $4.649 \pm 0.215$ & $4.673 \pm 0.383$ & $8.052 \pm 0.791$ & $7.708 \pm 0.316$ & $12.531 \pm 0.592$ & $11.921 \pm 0.624$ \\
& Testis & $0.197 \pm 0.016$ & $0.218 \pm 0.020$ & $0.282 \pm 0.015$ & $0.321 \pm 0.030$ & $0.432 \pm 0.048$ & $0.577 \pm 0.052$ \\
\cline { 2 - 8 } & $p$-value & 0.000 & 0.000 & 0.000 & 0.000 & 0.000 & 0.000 \\
\hline \multirow{4}{*}{8} & Blood & $0.056 \mathrm{v} 0.002$ & $0.038 \pm 0.001$ & $0.087 \pm 0.004$ & $0.061 \pm 0.005$ & $0.145 \pm 0.008$ & $0.094 \pm 0.003$ \\
& Liver & $7.747 \pm 0.406$ & $5.887 \pm 0.392$ & $18.583 \pm 0.841$ & $14.068 \pm 0.694$ & $26.941 \pm 1.513$ & $24.740 \pm 1.157$ \\
& Kidney & $8.905 \pm 0.457$ & $7.914 \pm 0.460$ & $18.673 \pm 1.512$ & $15.469 \pm 0.637$ & $28.495 \pm 1.844$ & $27.632 \pm 1.566$ \\
& Testis & $0.419 \pm 0.042$ & $0.292 \pm 0.023$ & $1.342 \pm 0.054$ & $1.146 \pm 0.078$ & $1.814 \pm 0.115$ & $1.523 \pm 0.078$ \\
\hline & $p$-value & 0.000 & 0.000 & 0.000 & 0.000 & 0.000 & 0.000 \\
\hline
\end{tabular}

G-I-1 : Cd $1.7 \mu \mathrm{g} / \mathrm{g}+\mathrm{DW}, \mathrm{G}-\mathrm{I}-2: \mathrm{Cd} 1.7 \mu \mathrm{g} / \mathrm{g}+\mathrm{KD}$

G-II-1 : Cd $3.4 \mu \mathrm{g} / \mathrm{g}+\mathrm{DW}, \mathrm{G}-\mathrm{II}-2: \mathrm{Cd} 3.4 \mu \mathrm{g} / \mathrm{g}+\mathrm{KD}$

G-III-1 : Cd $6.8 \mu \mathrm{g} / \mathrm{g}+\mathrm{DW}, \mathrm{G}-\mathrm{III}-2: \mathrm{Cd} 6.8 \mu \mathrm{g} / \mathrm{g}+\mathrm{KD}$.

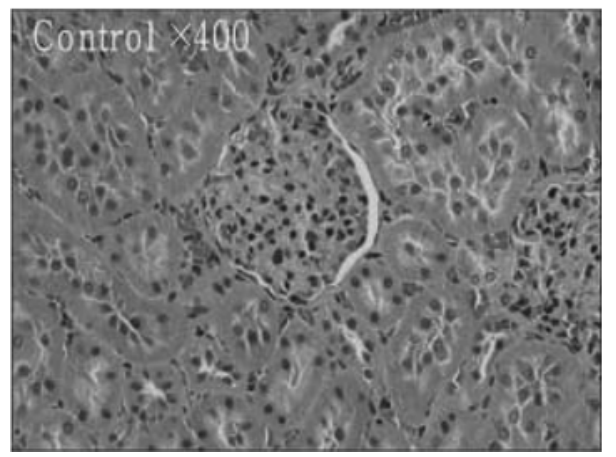

Fig. 1. Anormal histological feature of rat kidney (H\&E 400X). Normal glomeruli and tubules are observed.

\section{Histopathological findings of kidneys}

Rats' kidneys were observed using an optical microscope; as for the diluted water exclusively administered normal control group's kidneys (Fig. 1), glomeruli, distal convoluted tubules, and proximal tubules were well identified, while no tissue degeneration or necrosis was observed. As for the cadmium exclusively administered group G-I-1 (Fig. 2A), hemorrhagic necrosis in glomeruli and the swelling of tubules were observed; as for G-II1 (Fig. 3A), hemorrhagic necrosis in glomeruli and the swelling of tubules were found to be furthered. As for G-III-1 (Fig. 4A), hemorrhagic necrosis in glomeruli, epithelial shedding, and necrosis of tubules were observed. The cadmium and Gamdutang mixture-administered groups - GI-2 (Fig. 2B), G-II-2 (Fig. 3B) and G-III-2 (Fig. $4 \mathrm{~B})$ - were found to markedly diminish their damage levels, compared with the histopathological findings of the cadmium exclusively administered groups (Figs. 1 4). 

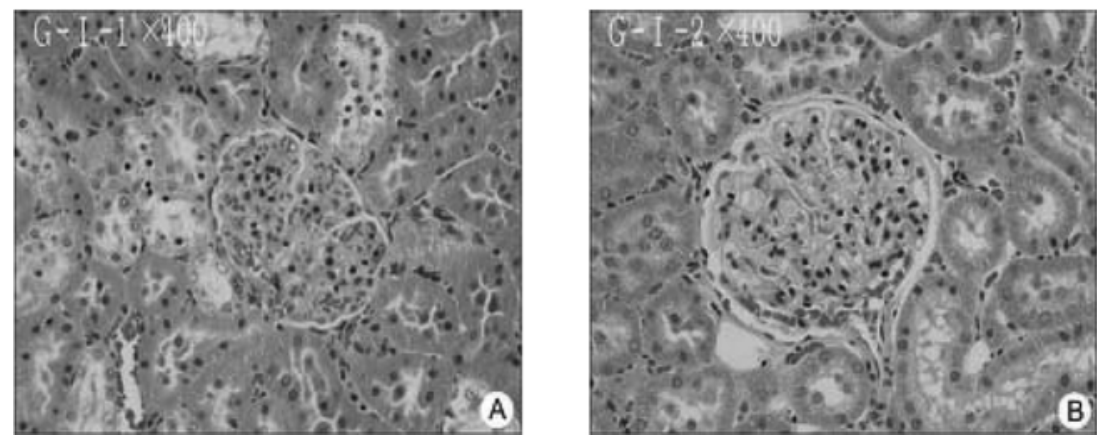

Fig. 2. Phtomicrograph of rat kidney treated by $\mathrm{Cd} 1.7 \mu \mathrm{g} / \mathrm{g} /$ day for 8 weeks (H\&E 400X). A. Cd + DW treated group. Cloudy swelling of tubules and hemorrhagic necrosis in glomeruli are observed. B. Cd + GD treated group. Glomerulus and tubules are observed normally.
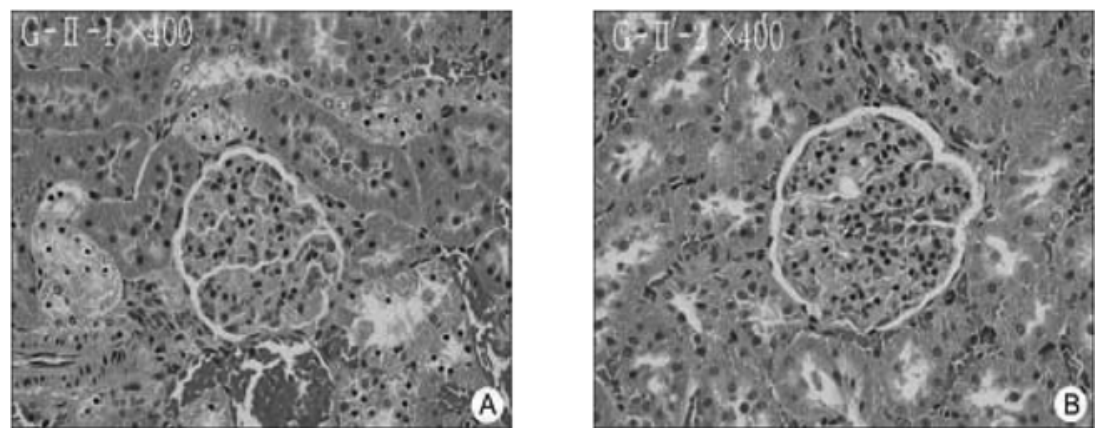

Fig. 3. Phtomicrograph of rat kidney treated by Cd $3.4 \mu \mathrm{g} / \mathrm{g} /$ day for 8 weeks ( $\mathrm{H} \& \mathrm{E} 400 \mathrm{X})$. A. Cd $+\mathrm{DW}$ treated group. Severe hemorrhagic necrosis in glomeruli and swelling of tubules are observed B. Cd + GD treated group. Mild hemorrhagic necrosis in glomeruli and swelling of tubules are observed.
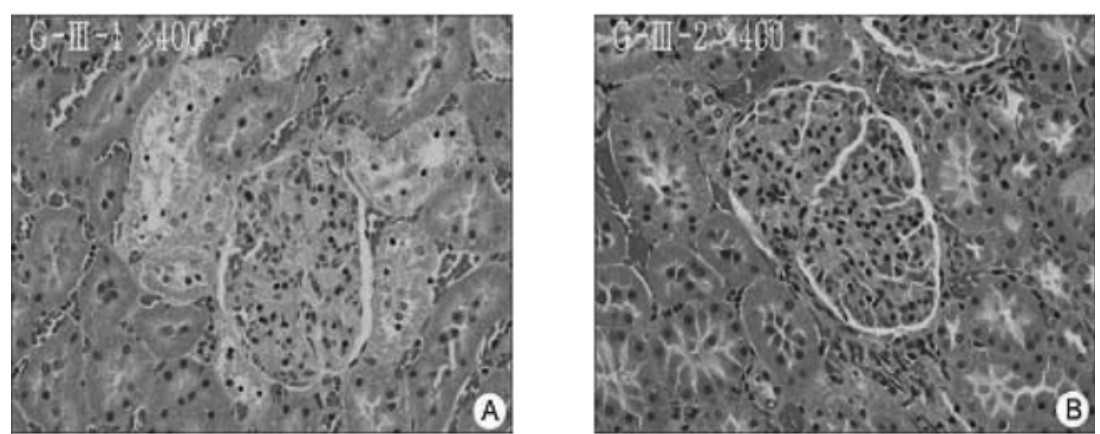

Fig. 4. Phtomicrograph of rat kidney treated by Cd $6.8 \mu \mathrm{g} / \mathrm{g} /$ day for 8 weeks (H\&E 400X). A. Cd + DW treated group. Multiple foci of necrosis, hemorrhagic necrosis in glomeruli and cloudy swelling of tubules are observed. B. $\mathrm{Cd}+\mathrm{GD}$ treated group. Mild hemorrhagic necrosis in glomeruli and swelling of tubules are observed.

\section{Discussions}

This research sought to determine what effects the administration of Gamdutang (a bio-substance known to have the effect of detoxication) into the body would have on the absolution of cadmium into the body and the accumulation of cadmium in the body. As for a change in weight (Table 2), both the control group and the test groups tended to raise their weight significantly with the increase of 
the number of week, and the cadmium exclusively administered control groups (G-I-1, G-II-1, and GIII-1) tended to decrease their weight significantly, compared with the control group; however, G-I-2 and G-II-2, of the cadmium and Gamdutang mixture-administered groups, did not show a significant difference in weight, and G-III-2 tended to decrease their weight significantly. Thus, when administered with a mixture of Gamdutang and cadmium with the cadmium concentration set at $1.7 \mu \mathrm{g} / \mathrm{g}$ and $3.4 \mu \mathrm{g} / \mathrm{g}$, respectively, it is deemed that Gamdutang, which has the effects of nourishment and detoxication, increases the weight; when although Gamdutang is administered, highconcentration cadmium is administered, it is deemed that Gamdutang has no effects on rats' weight gain. These results are similar to the report that when higher-concentration cadmium is administered, if the administration period increases, the cadmium accumulation will rise; thus, the toxicity increases, causing a change in nutrient absorption and metabolism in the body, which leads to a decrease in diet efficiency, hence slowing weight gain. ${ }^{21,22)}$

As for the accumulation of cadmium in blood, livers, kidneys, and testis (Tables 3-6), with all test groups, as the cadmium administration period increased, cadmium concentration in blood and these organs tended to rise; also, as the cadmium administration concentration increased, the cadmium accumulation concentration rose. Compared with the cadmium exclusively administered groups, the cadmium and Gamdutang mixture-administered groups, with an increase in cadmium administration period, decreased cadmium accumulation in blood, livers, kidneys, and testis. This is deemed to imply that Gamdutang has the effect of activating the circulation of substances, ${ }^{20}$ and of resisting the absorption of cadmium into digestive organs. ${ }^{12,23)}$

In the comparision of cadmium accumulation in blood and diverse organs (Table 7), for all test groups, in the 1st and 2nd weeks of experiment, the cadmium accumulation ranking was livers, kidneys, testis and blood in this order. As for the cadmium exclusively administered groups, in the 8th week, cadmium accumulation was greater in kidneys than in livers, determining cadmium accumulation ranking in the order of kidneys, livers, testis, and blood; as for the cadmium and Gamdutang mixture-administered groups, in the 4th week, cadmium accumulation was greater in kidneys than in livers, determining cadmium accumulation ranking in the order of kidneys, livers, testis and blood. These results are the same as those of numerous previous researches ${ }^{24,25)}$ that cadmium, when absorbed into the body, is accumulated mainly in the liver and the kidney, as well as consistent with the reports that cadmium, when orally administered artificially, cadmium is accumulated primarily in the liver and the kidney $^{26,27}$ Also, the experimental results herein are the same as the report that the group, to which garlic oil and vitamin A were administered as protective substances, accumulated more cadmium in the kidneys than in the livers beginning with the 4th week, and the cadmium exclusively administered groups beginning with the 8 th week. ${ }^{28)}$

Kidneys of experimental animals were observed through an optical microscope; as for the cadmium exclusively administered group G-I-1 (Fig. 2A), hemorrhagic necrosis in glomeruli and the swelling of tubules were observed; as for G-II-1 (Fig. 3A), hemorrhagic necrosis in glomeruli and the swelling of tubules were found to be worse. As for G-III-1 (Fig. 4A), hemorrhagic necrosis in glomeruli, epithelial shedding and necrosis of tubules were observed. However, as for the cadmium and Gamdutang mixture-administered groups (G-I-2 (Fig. 2B), G-II-2 (Fig. 3B) and GIII-2 (Fig. 4B), the damage was markedly reduced compared with the histopathological findings of the cadmium exclusively administered groups. These results are similar to the reports that the kidney damage caused by cadmium hurt mainly the proximal tubules and, in this area, atrophy and degeneration, as well as the vacuolation of tubule cells, were caused, ${ }^{29)}$ and that in the experiment of administering a mixture of safflower seed powderadded diet and cadmium in drinking water to mice for 8 weeks, as for the cadmium exclusively administered group, observed in the kidneys were the expansion of glomeruli, degeneration and necrosis of tubules, epithelial shedding and vocuolation in tubules were observed. ${ }^{30)}$ Also, when the aforementioned histopathological observation and findings are compared with cadmium accu- 
mulation in various organs as shown in this experiment, they are deemed to have a relevancy with the results that compared with the cadmium exclusively administered groups (G-I-1, G-II-1 and G-III-1), the cadmium and Gamdutang mixtureadministered groups (G-I-2, G-II-2 and G-III-2) accumulated less cadmium.

Putting together all of these discussions above, Gamdutang is deemed to have the effect of restraining the accumulation of cadmium in rats' blood, livers, kidneys and testis when lowconcentration cadmium is administered to the rats' bodies. However, this research has limitations in giving a clear explanation as to the mechanism of what ingredients in Gamdutang have effects on the absorption and accumulation of cadmium. This mechanism should be disclosed through additional experiments in the future.

\section{References}

1. Sendelbach, L. E. and Klaassen, C. D. : Kidney synthesizes less metallothionein than liver in response to cadmium chloride and cadmium. metallothionein. Toxicology and Applied Pharmacology, 92, 95-102, 1988.

2. Hammond, P. B. and Foulkes, E. C. : Metal ion toxicity in man and animals. In ; H Siegel (ed), metal ions in biological systems. Vol. 20, Marcel Dekker, New York, p177, 1986.

3. Lee, J. W., Jang, B. K., Pack, J. A., Pack, J. Y., Kim, W. J. and Woo K. M. : The mechanism of the neurotoxicity induced by cadmium. Korean Journal of Environmental Toxicology, 19(3), 279-286, 2004.

4. Cho, Y. C. : In vitro magnetometry, LDH activity and apoptosis as indices of cytotoxicity in alveolar macrophages exposed to cadmium chloride. Korean Journal of Environmental Health, 26(4), 115-121, 2000.

5. Dudley, R. E., Svoboda, D. J. and Klaassen, C. D : Acute exposure to cadmium causes severe liver injury in rat. Toxicology and Applied Pharmacology, 65, 302, 1982.

6. Kim, E. J., Kim, S., Yang, E. J., Han, S. R., Kim, S. I. and Kim, W. S. : A study on the congenital anomalies induced by cadmium chloride. Korean Journal of Physical Anthropologists, 13(2), 239251, 2000.

7. Webster, W. S. : Cadmium induced fetal growth retardation in the mouse. Archives of Environmental and Occupational Health, 32, 16-22, 1978.

8. Klassen, C. D., Amdur, M. O. and Doull, J. : Casaret and Doull's Toxicology, 3rd ed., Macmillan, p23-100, 1986.
9. Ando, M., Matsui, S., Jinno, H. and Takeda, M. : Urinary excretion of cyclic AMP in cadmiumintoxicated rats. Journal of Toxicology and Environmental Health, 27, 307-315, 1989.

10. Prasada Rao R. V. V., Jordan, S. A. and Bhatnagar, M. K. : Combined nephrotoxicity of methylmercury lead and cadmium in pekin ducks, metallothionein, metalinteractions, and histopathology. Journal of Toxicology and Environmental Health, 26, 327-348, 1989.

11. Hamer, D. H. : Metallothionein. Annual Review of Biochemistry, 55, 913-951, 1986.

12. Onosaka, S., Tanaka, K. and Cherian, M. G : Effects of cadmium and zinc on tissue of metallothionein. Journal of Environmental Health Perspectives, 54, 67-72, 1984.

13. Nomiyama, K. and Nomiyama, H. : Aggravated toxicities of cadmium chloride and mercury(II) chloride in zinc deficient rats. Acta Pharmacological Toxicology Supplement, 59(7), 75-78, 1986.

14. Ahokas, R. A., Dilts, P. V. and Lahaye, E. B. : Cadmium induced fetal growth retardation: Protective effect of excess dietary zinc. American Journal of Obstetrics and Gynecology, 136, 216-221, 1980.

15. Schroeder, H. A., Frost, D. V. and Balassa, J. J. : Essential trace metals in man. Selenium. Journal of Chronic Diseases, 23, 227-243, 1970.

16. Suh, E. S. and Lim, J. P. : Effects of YukmijihwangTang on the Hepatic Microsomal Function of Cdpoisoned Rat. Korean Journal of Pharmacognosy, 30(3), 250, 1999.

17. Lee, S. D. : A Study on the preventive effect of Kamdoo decoction on the subacute lead toxicity in rats. Graduate School of Public Health Seoul National University, 1993.

18. Chung, S. H. : Effects of Glycyrrhizae Radix and Semen Glycine extraction the hepatic injuries induced by $\mathrm{CCl}_{4}$ in rats. Graduate School of Public Health Chungnam National University, 1999.

19. Han, S. H. : Antitumor activity of Gamdutang aquaacupuncture solution. Graduate School of Oriental Medicine Dongguk University, 1999.

20. Committee for Translating Donguibogam into Korean : Donguibogam. Namsandang. 1994.

21. Rho, J. H., Han, C. K., Seong, K. S. and Lee, N. H. : Effects of pork on cadmium detoxification in rats. Korean Journal of the Food Science and Animal Resources, 25(4), 373-382, 2005.

22. Choi, S. I., Lee, J. H. and Lee, S. R.: Effect of Green tea beverage for the removal of cadmium and lead by animal experiments. Korean Journal of the Food Science and Technology, 26(6), 745-749, 1994.

23. Cantilena, L. R. and Klassen, C. D. : Decreased effectiveness of chelation theraphy with after acute cadmium poisoning. Toxicology and Applied Pharmacology 43, 173-180, 1982.

24. Combs, D. K., Goodrich, R. D. and Meiske, J. C. : 
Influence and dietary zinc of cadmium on hair and tissue mineral concentration in rat and goats. Journal of Animal Science, 56, 184-193, 1983.

25. Sharma, R. P, and Street, J. C. : Public health aspects of toxic heavy metals in animal feed. American Journal of Veterinary Medical Association, 177, 149-153, 1980.

26. Agarwal, A. K. : Metabolic alterations in liver and testes of adult and new born rats following cadmium administration. Bulletin of Environmental Contamination and Toxicology, 40, 569-575, 1988.

27. Dudley, R. E., Gammal, L. M. and Klaassen, C. D. : Cadmium-induced hepatic cadmium metallothionein in nephrotoxicity. Toxicology and Applied Phar- macology, 77, 414-426, 1985.

28. Kim, P. G. : Effects of Garlic Oil (diallyl disulfide)/ Vitamin A (retinal acetate) on heat shock protein induction in cadmium treated rats. Journal of Food Hygiene and Safety, 13(2), 171-187, 1998.

29. Nishizumi, M. : Electron microscopic study of cadmium nephrotoxicity in the rat. Archives of Environmental and Occupational Health, 24, 215-225, 1972.

30. Jang, J. S. and Kwon, O. D., : Histopathological studies on the effect of Korean Safflower (Carthamus tinctorious L.) seed powder on cadmium poisoning in mice. Journal of Veterinary Clinical Medicine, 18(2), 116-123, 2001. 